\title{
Guest editorial and introduction: STEM and STEM education
}

\author{
Judy Anderson ${ }^{1}$ (D) \\ Published online: 18 September 2020 \\ (C) Australian Curriculum Studies Association 2020
}

Science, Technology, Engineering and Mathematics (STEM) have featured in the media over recent years as politicians have called for increased investments in business and industry to ensure Australia's competitiveness in global markets. Such interest is almost invariably followed by calls for improvements in students' results on international tests in mathematics and science, improvements in the teaching of the STEM subjects with more qualified teachers, and increased enrolments in STEM degrees to fill shortages of qualified mathematicians and scientists.

Stakeholders tend to seize such opportunities requesting education systems to improve teaching and learning and 'return to the basics' as if the curriculum has somehow been changed so that students do not need to learn fundamental concepts. The focus of the STEM curriculum subjects has always required the learning of important content and processes. What appears to be different in recent times is a call for greater focus on connecting knowledge across the STEM subjects, on using STEM knowledge flexibly to solve more authentic problems, on developing essential skills for more technologically advanced work environments, and on understanding the STEM career possibilities available in changing workplaces. Such calls for change in STEM education have led to innovations in teaching and learning by teachers of the STEM subjects.

Since the increased focus on STEM education in Australia, many STEM teachers have been investigating ways to adapt their programs and practices to improve student motivation and engagement in STEM and to increase opportunities for students to experience the practices of STEM professionals through real-world problems. The collection of papers in this issue of Point and Counterpoint present some of these innovations but also raise important questions still to be addressed. Determining what STEM curriculum might look like in

Judy Anderson

judy.anderson@sydney.edu.au

1 The University of Sydney, Sydney, New South Wales, Australia schools is a key issue if teachers are to design learning experiences which meet stakeholder expectations. While the mandated curriculum designed as separate STEM subjects must still be addressed, teachers do have flexibility to design tasks, lessons and units of work which connect and integrate aspects of each of the STEM subjects. Designing and implementing integrated STEM curriculum is considered in Anderson's paper in this collection while Lyons presents a range of different approaches to designing integrated STEM curriculum. His Russian Doll analogy raises many questions about the roles of each of the STEM subjects when solving real-world problems. Cameron's paper focusinges more on the role of technology curriculum in preparing the workers of the future. She also provides useful background information on the Australian curriculum and how the three 'dimensions' structure provides opportunities to develop twenty-first Century skills.

The final two papers in this collection on STEM education present results from two studies investigating the impact of connecting with community and industry on teaching and learning. Murphy explored how successful schools used local community engagement to develop STEM experiences for their students. While there was evidence in the schools of quality teaching and learning of the separate STEM subjects, this was accompanied by local problems involving real-world scenarios for students to explore. Hobbs and Kelly present the results of their work with schools in the Geelong area in Victoria as they connected project schools with business partners who worked collaboratively with teachers to develop new curriculum approaches. While the work was complex and time consuming, these stakeholder partners were highly valued and able to make worthwhile contributions to the school's STEM efforts.

There is still much to learn about STEM education and how it might build on and enhance the teaching and learning of the separate STEM subjects, but there are many Australian researchers contributing substantially to these efforts (e.g., English 2016; English and Moore 2018; Freeman et al. 2015; Jordan 2019; Lowrie et al. 2017; Rennie et al. 2018). These 
researchers are making a valuable contribution to our understanding of what is possible for STEM education, how schools might address connected STEM curriculum, and the challenges for teachers. Their work builds on the many approaches published elsewhere but particularly from the USA where the STEM movement appears to have begun (Li et al. 2020).

\section{References}

English, L. D. (2016). STEM education K-12: Perspectives on integration. International Journal of STEM Education, 3(1), 1-8. https:// doi.org/10.1186/s40594-016-0036-1.

English, L. D., \& Moore, T. (Eds.). (2018). Early engineering learning. Singapore: Springer. https://doi.org/10.1007/978-981-10-8621-2_13.

Freeman, B., Marginson, S., \& Tytler, R. (2015). The age of STEM. Oxon: Routledge.
Jordan, K. (2019). Reading STEM as discourse. In T. Barkatsas, N. Carr, \& G. Cooper (Eds.), STEM education: An emerging field of inquiry (pp. 45-60). Leiden, The Netherlands: Koninklijke Brill.

Li, Y., Wang, K., Xiao, Y., \& Froyd, J. E. (2020). Research and trends in STEM education: A systematic review of journal publications. International Journal of STEM Education, 7, 11. https://doi.org/ 10.1186/s40594-020-00207-6.

Lowrie, T., Downes, N., \& Leonard, S. (2017). STEM education for all young Australians: A bright spots learning hub Foundation paper, for SVA, in partnership with Samsung. Canberra, Australia: University of Canberra STEM Education Research Centre.

Rennie, L., Venville, G., \& Wallace, J. (2018). Making STEM curriculum useful, relevant and motivating for students. In R. Jorgensen \& K. Larkin (Eds.), STEM education in the junior secondary: The state of play (pp. 91-110). Singapore: Springer Nature.

Publisher's note Springer Nature remains neutral with regard to jurisdictional claims in published maps and institutional affiliations. 